\title{
Long-term changes in the within-season temporal profile of southwest monsoon over western India
}

\author{
Satyendra Bhandari ${ }^{1}$, Rohit Srivastava ${ }^{1, *}$ and Vikram Mehta ${ }^{2}$ \\ ${ }^{1}$ Indian Centre for Climate and Societal Impacts Research (ICCSIR) Mandvi, Kachchh, Gujarat 370 465, India. \\ ${ }^{2}$ The Centre for Research on the Changing Earth System (CRCES), Catonsville, Maryland, USA. \\ *Corresponding author. e-mail: rohit.srivastava@iccsir.org
}

This paper presents results of a study of long term trends in the characteristics of the within-season temporal profile of southwest monsoon rainfall over western India during the last five decades in relation to global warming induced regional climate change. In contrast to recent climate change analyses and projections, no significant long-term trends have been observed in this study. Slow decadal scale variations observed are analysed in relation to Pacific Decadal Oscillations (PDO). Daily variations in rainfall anomaly show opposite characteristics during negative and positive phases of PDO. The above-normal rainfall $(>25 \%)$ is found during the starting phase of monsoon in negative PDO. Over the last decade, i.e., during 2000-2007, the seasonal rainfall amount, as well as seasonal span of southwest monsoon over western India is indicative of a gradual increase.

\section{Introduction}

Southwest (or the Indian summer) monsoon, along with its variability on different space and time scales, over India represents a highly significant weather and climate phenomenon affecting the life and economy of India in a variety of ways. The forecast of seasonal total all-India average quantum of rainfall during the southwest monsoon serves as a macro input for overall planning. However, what is more crucial for the agricultural operations is the within-season day-to-day temporal profile of rainfall amount across different parts of the country, since this evolution impacts not only the agricultural sowing operations, but also crop-health, crop yield and food production. This information is also necessary for optimal planning water storage for irrigation, hydroelectric power generation, flood forecasting and other societal sectors.

Over the last two decades, efforts have been made to understand the impact of greenhouse and aerosol-induced climate change on the spatio-temporal pattern of monsoon rains over the country (e.g., Ramanathan et al. 2001). Complicating factors like increasing urbanization also play a significant role (Kishtawal et al. 2010). Most of the studies (e.g., Krishna Kumar et al. 2011; Sinha et al. 2012), particularly global climate model based projections of future climate, have concentrated on simulating and analysing the seasonal total rainfall projections over large spatial regions of the country.

In addition to the amount of seasonal rainfall associated with southwest (SW) monsoon, attention has also been paid to the projected change in the intensity distribution of rainfall. Such projections show that the fraction of high-intensity rainfall events is steadily increasing, at least regionally, consistent with the projections of a warmer surface and atmosphere. The results so far have been ambiguous due to extreme space-time heterogeneity of rainfall over Indian landmass (Jagannathan and

Keywords. Southwest monsoon; decadal climate variability; Pacific decadal oscillations. 
Bhalme 1973; Goswami et al. 2006; Satyanarayana and Srinivas 2008; Ghosh et al. 2009, 2011).

From agricultural applications point of view, it is equally important to analyse whether, under the global warming and aerosol-induced climate change scenarios, the within-season temporal profile of SW monsoon rainfall is undergoing any systematic change/shift. Over the last many years, a general impression seems to be gaining ground that the SW monsoon rains are getting delayed in time and the peak rainfall is occurring later in August and September months rather than in July. It has generally been noted that the withdrawal of SW monsoon is getting delayed over certain parts of the country (Guhathakurta et al. 2015).

One aspect of the change in the temporal evolution of SW monsoon rainfall was analysed by Tyagi et al. (2011). They looked at the changes in the dates of onset of SW monsoon over the Kerala Coast, using Pentad precipitation data from 569 stations spread all over the country, for the period 1971-2000. Their study attempted to analyse the differences between onset dates defined traditionally for 1900-1940 period and a new definition used for the 1971-2000 period. Regions where significant changes were noticed were parts of south peninsula, western parts of central India and adjoining NW India. Over these regions, the onset was delayed by $10-15$ days with a large standard deviation in the number of days. This study, however, did not address the issue of changes in onset dates specifically with respect to global warming and climate change. Anderson and Nash (2013) also analysed the date of onset of the SW monsoon in western India in view of is critical importance for farmers. Their study suggests that the climatic regime that governs monsoon advance over western India did not change substantially between 1781 and 1955.

Pacific decadal oscillation (PDO) is characterized by warming and cooling of the northern pacific region (Mantua et al. 1997). PDO is inter-decadal oscillations different from inter-annual oscillation (e.g., El Niño Southern Oscillation (ENSO)). The vulnerability of SW monsoon towards drought is found to be more probable when El Niño events occur during warm phase of PDO (Krishnan and Sugi 2003).

In this context, it would be interesting to analyse the changes, if any, in the within-season 'temporal profile' of SW monsoon rainfall during the season over different regions of India using the daily gridded rainfall data available (Rajeevan et al. 2006) covering last many decades from India Meteorological Department (IMD).

In this study, we focus on western India, in view of large and extreme variability associated with SW monsoon and its critical importance for agricultural operations over this region.

\section{Data analysis}

In the present study, we have used the gridded rainfall dataset available from IMD (Rajeevan et al. 2006). It provides daily rainfall values at $1^{\circ} \times 1^{\circ}$ grid over the Indian landmass for the 19512007 period.

Here, we present the analysis of the seasonal rainfall distribution in time over the $8^{\circ} \times 7^{\circ}$ western Indian region bounded by lat.: $20.5-28.5^{\circ} \mathrm{N}$ and long.: $66.5-73.5^{\circ} \mathrm{E}$, for the $1951-2007$ period (figure 1). The June-September rainfall climatology shows the lowest rainfall over the study region when compared to other regions in Indian subcontinent (figure 1). In order to analyse and study the within-season time profile, we set some time markers starting from June 1st, when the accumulated rainfall over the region crosses a certain percentile/threshold of the total rainfall for the season. These markers are derived by analysing the cumulative seasonal rainfall distribution as a function of days from June 1 . We have used 1\%, 25\%, 50\% and $75 \%$ percentiles as time markers and analysed their variation from year to year over the entire period.

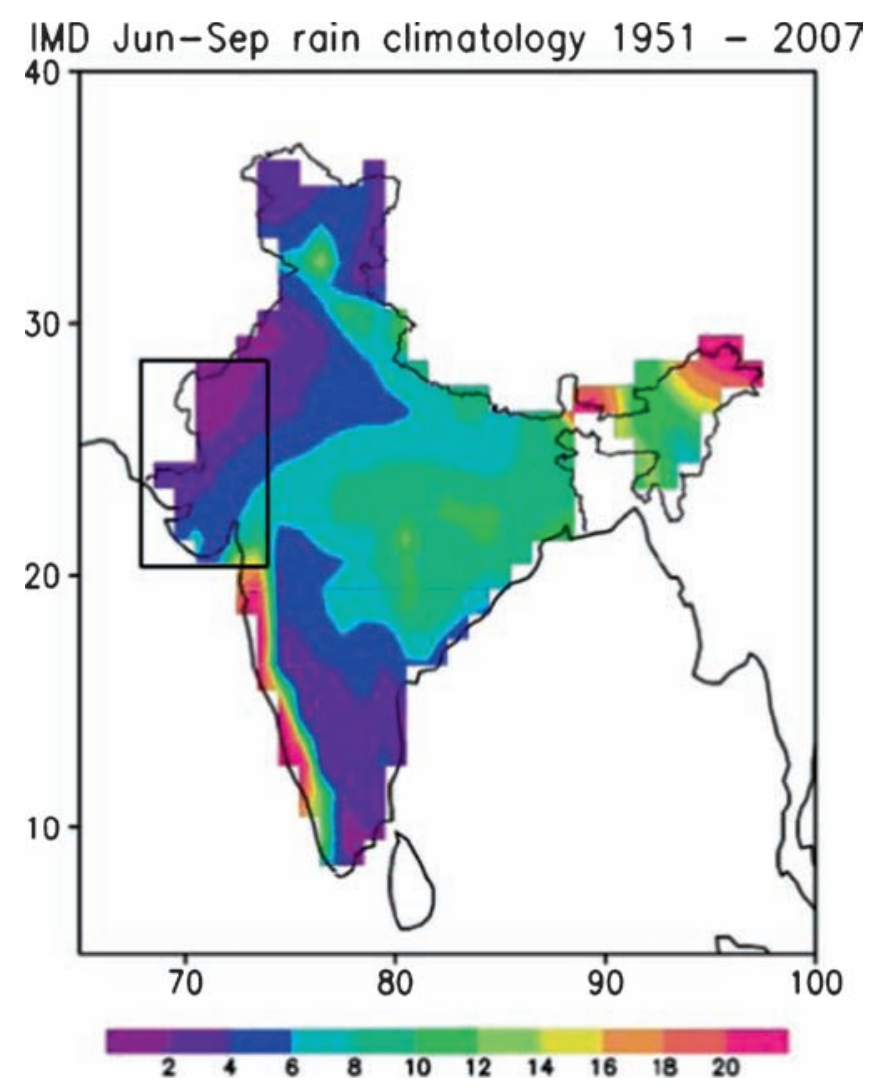

Figure 1. Rainfall (mm/day) climatology over Indian region during SW monsoon (June-September) season of 19512007. The rectangular box represents the study region. 


\section{Results and discussion}

The climatologically averaged daily distribution of rainfall over the SW monsoon season over western Indian region for the 1951-2007 period are shown in figure 2. The corresponding cumulative distribution showing time markers discussed above is also shown superposed.

The climatological mean total seasonal rainfall for the 1951-2007 period for the western Indian region under consideration is about $500 \mathrm{~mm}$. The $25 \%, 50 \%$ and $75 \%$ percentiles occur, on an average, on July 7 (day 37 since June 1), July 27 (day 56) and August 21 (day 82), respectively. The distribution of daily rainfall shown in figure 2 , gives the suggestion of existence of short tails before the beginning and after the end of the season. However, since the SW monsoon season is rigidly defined as June 1st to September 30th, we have analysed the data for the June 1-September 30 period only.

Analysis of time variation of these markers over the entire period 1951-2007 is presented in figure 3 . The top panel of figure 3 shows the year-to-year variation of dates of crossing the four percentiles defined earlier, i.e., $1 \%, 25 \%, 50 \%$ and $75 \%$ over the entire period of analysis. The first $1 \%$ marker effectively represents the 'onset' of SW monsoon over the western Indian region selected for the study. The average occurrence date is centered around 10th June over the region of interest, with a deviation of nearly \pm 5 days. No discernible long term trend is seen in the onset dates as defined in this study. Similar behaviour is present in the curve for $25 \%$ marker. However, during the last decade (2000-2007), the 25\% level is achieved later and later in time. Of course, this is not a monotonous increase - the behaviour is oscillatory in nature. It may be noted that this period includes two major rainfall deficient years - 2002 and 2004 - both on all-India basis as well as for western India.

Approximately similar behaviour is observed for the $50 \%$ and $75 \%$ percentile markers, except that the amplitude of fluctuations is relatively large compared to the 25 percentile. For $50 \%$, the RMS is \pm 5 days, and for $75 \%$ maker it is more like $\pm 7-8$ days. Further, both $50 \%$ and the $75 \%$ marker curves seem to have undergone a small decreasing trend till about 1990, followed by a slowly increasing trend till the end of the data record. A careful scrutiny indicates that the primary delay occurs after the initial $25 \%$ accumulation, which is achieved early. Overall, the time duration between $25 \%$ and $75 \%$ level is reached much more gradually in the later half of the observation record (19902007) than in the earlier period (1970-1990). The pattern over the 1951-1970 period seems to have returned again after 1990 .

The bottom panel of figure 3 shows variation of total seasonal rainfall for the period 1951-2007. An approximately decadal scale quasi-periodic variation is seen, with higher rainfall amounts during 1952-1962, 1975-1984, and 1986-1996. Again, an increasing trend is seen over the last decade in the total rainfall. Overall, the rainfall was largely
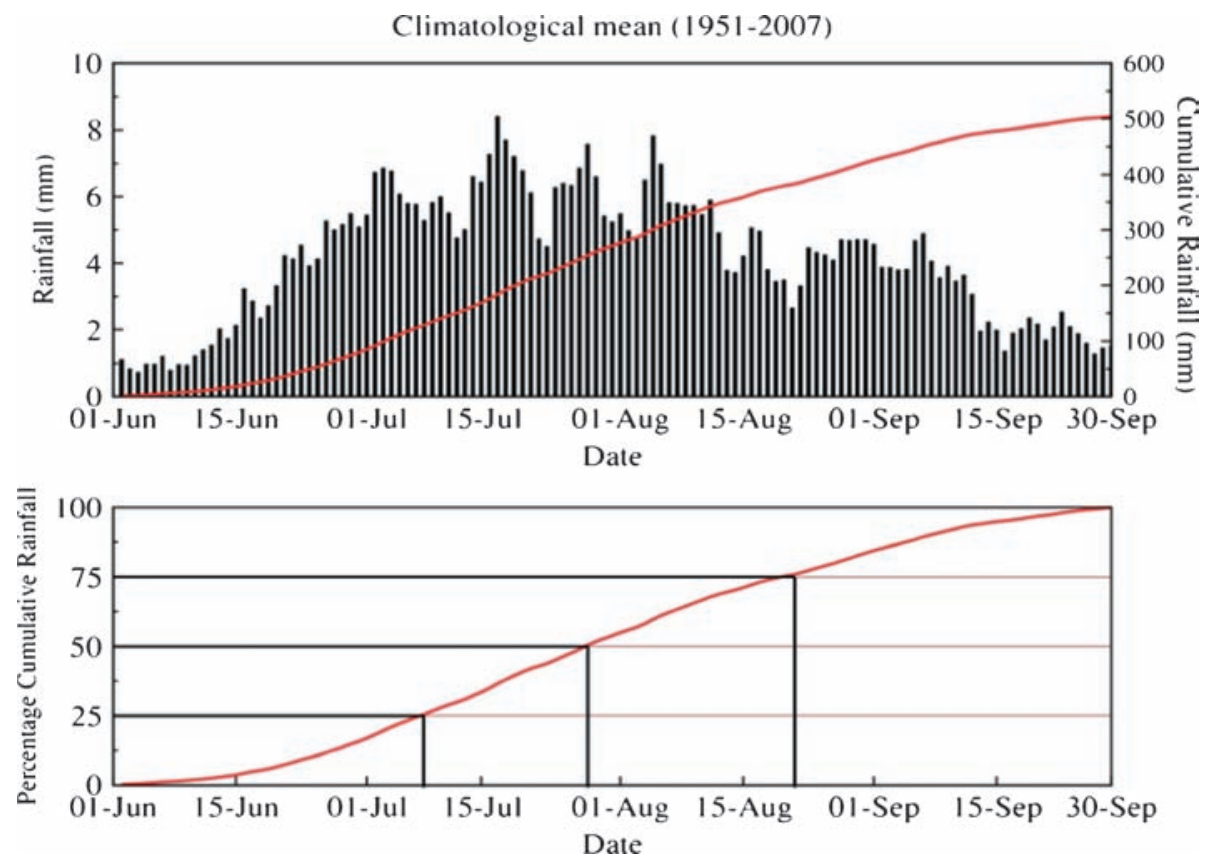

Figure 2. Top panel: Climatological averaged seasonal distribution of daily rainfall amount associated with the SW monsoon over the western Indian region. Cumulative distribution curve (red) is shown superposed. Bottom panel: Cumulative seasonal distribution of daily rainfall showing the dates (time markers) associated with 25, 50 and 75 percentiles. 


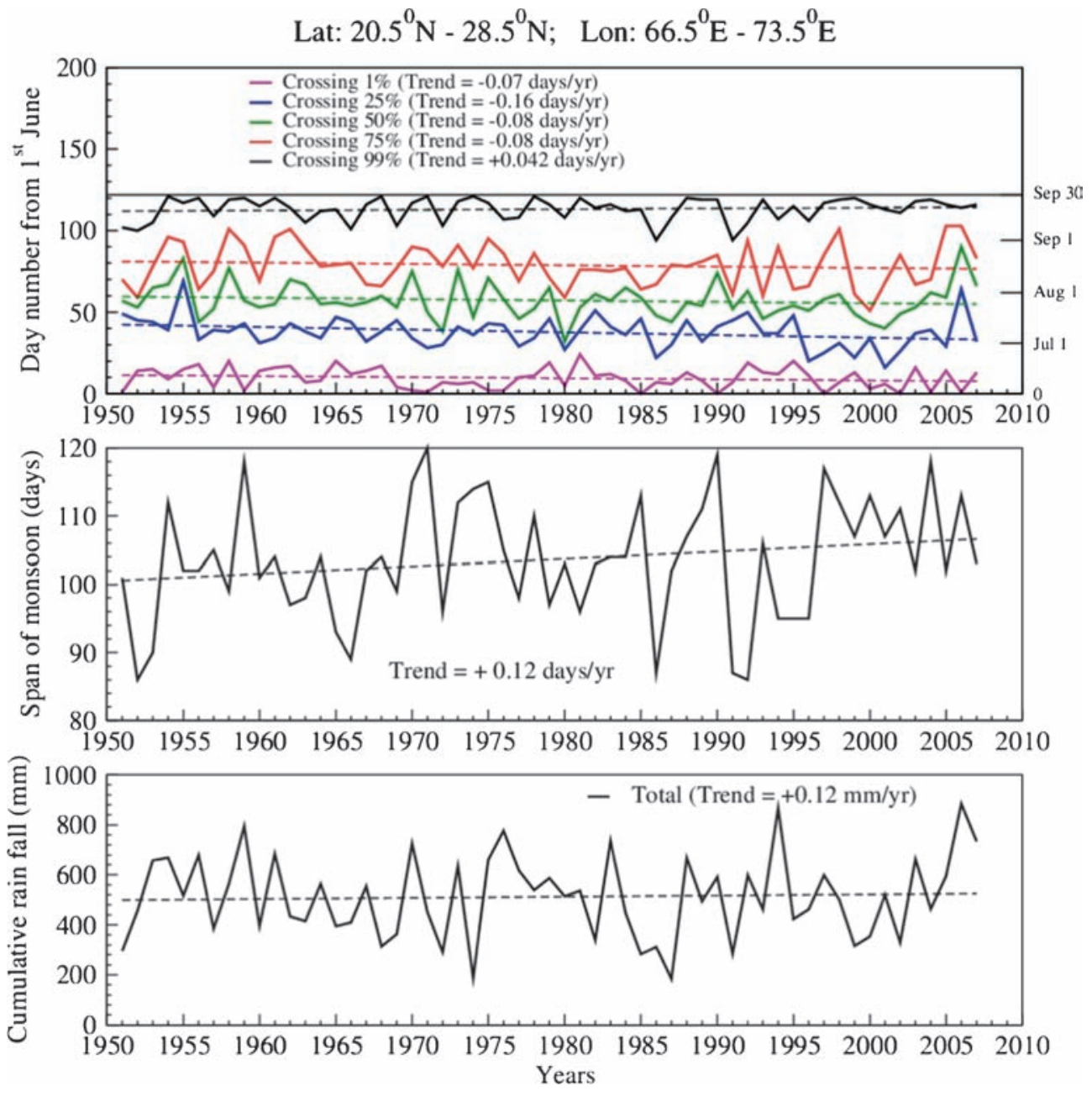

Figure 3. Top panel: Dates (or days from June 1) of acquisition of 1, 25, 50 and $75 \%$ cumulative rainfall percentiles over western Indian region over the period 1951-2007. Middle panel: Seasonal span of the SW monsoon rainfall as defined by 1 and $99 \%$ percentiles. Lower panel: Yearly cumulative seasonal total SW monsoon rainfall over western Indian region from $1951-2007$.

deficient during the 1960s and 1980s. After 2000, the seasonal rainfall shows a systematically increasing trend. Similar increasing trend during summer season in surface temperature and rainfall over NW India was reported by Yadav (2016). The increase in surface temperature over Iran gives rise to increases in the tropospheric temperature along the vertical cross-section of atmosphere with maximum warming at lower troposphere which intensify surface low-pressure area over Iran and results anomalous cyclonic circulation with northerlies and westerlies over Persian Gulf and north Arabian Sea, respectively (Yadav 2016). The convergence of these winds towards NW India favoured deep convection over the NW Indian region (Yadav 2016).

The middle panel in figure 3 shows the span of SW monsoon season over western Indian region of interest. This is somewhat redundant to analyse since the span of data is already pre-defined as June 1-September 30 (i.e., 122 days) for the entire country. Nevertheless, it is interesting to see the significant deviations in $99 \%$ percentile, which is achieved somewhat early often during the middle of 1960 and 1980s period, as against consistently later during the period 1998 onwards. The years 1965, 1986, 1992 and 1995/1996 show unusually early end of the season. The 'span' and 'total' seasonal rainfall appear to be correlated - the years with significantly early end of the season are associated with low total seasonal rainfall $(450,250,350$ and $425 \mathrm{~mm}$ respectively, as compared to the climatological average of nearly $500 \mathrm{~mm}$ ).

Overall, the last decade (1998-2007) has shown a different nature of variability than earlier decades with a wetter and longer SW monsoon season over western India. This implies that a higher fraction of rainfall is realized later in the season. In general, over the last 8-10 years, all the markers, except the $1 \%$ marker, indicate a shift towards later dates. Statistical analysis at the annual scale shows that the span of the monsoon season is 
increasing at +0.12 days/year. Further analysis, with more recent data, is required to substantiate this behaviour.

In the following, we look at the observed decadal variability in within-season temporal profile of rainfall over the western Indian region in relation to well known influence of PDO. Figure 4 shows the cumulative rainfall distribution composited for negative and positive PDO years. In order to analyse the effect of PDO, we have compared the cumulative distribution for positive, negative phases of PDO and the overall climatology. This is shown in the bottom panel. PDO interestingly shows a small but definitive influence that takes place and is confined to the first half of the month of August. The daily variations of percentage rainfall anomalies during negative and positive phases of PDO are shown in figure 5 . There are out of phase changes that can be seen in rainfall anomalies during negative and positive phases of PDO. The above-normal rainfall $(>25 \%)$ is found during the starting phase of monsoon, while below-normal rain can be seen during the mid-monsoon (15 July-15 August) in negative phase of PDO (figure 5).

There is inverse relationship between the PDO and the Indian monsoon rainfall. A positive (negative)

Negative PDO phase (1961 - 2007)

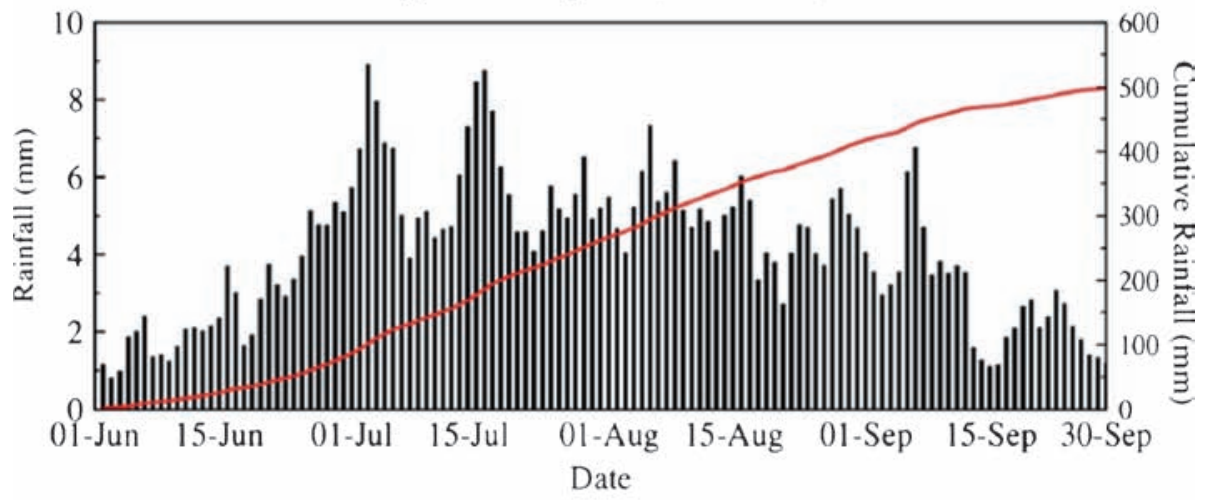

Positive PDO phsae (1961 - 2007)
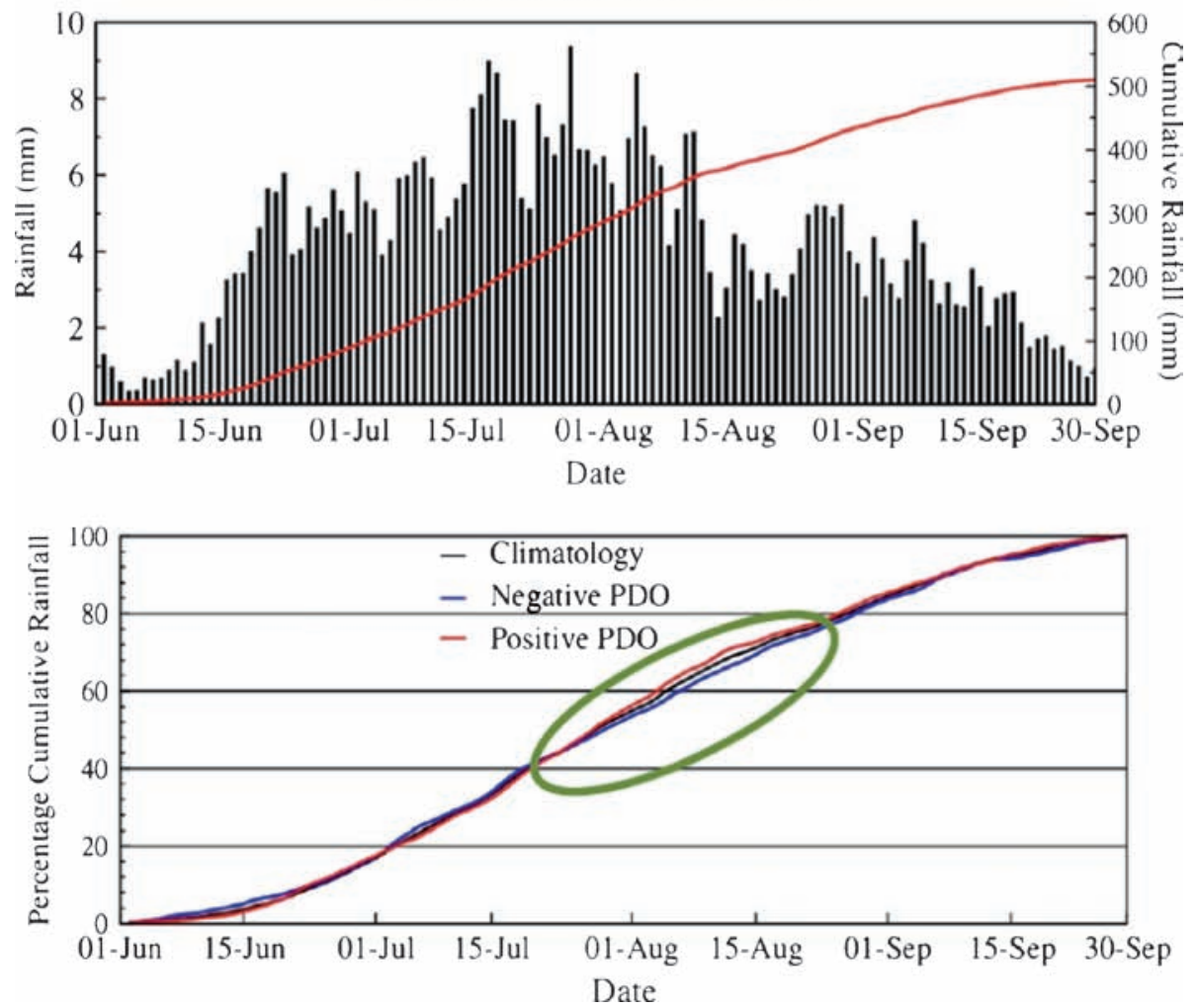

Figure 4. Temporal profile of SW monsoon rainfall over western Indian region in relation for negative and positive phases of PDO (top and middle panels respectively). Climatological cumulative percentage of rain for all the years and average cumulative rainfall during negative and positive phases of PDO (bottom panel). 

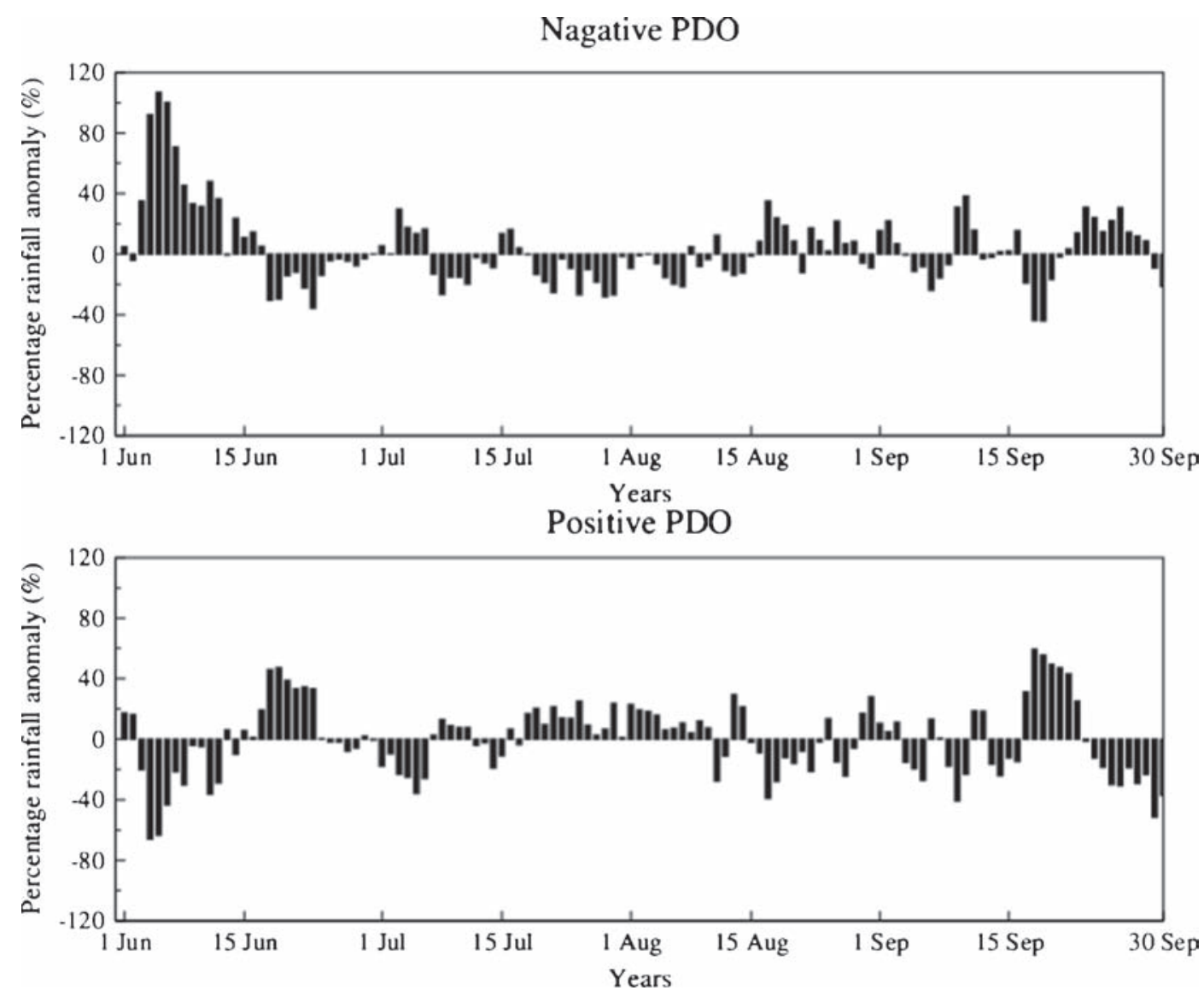

Figure 5. Daily variability in percentage rainfall anomaly (\%) during negative phase of Pacific Decadal Oscillation (PDO) (top panel) and positive phase of PDO (bottom panel).

phase of the PDO is characterized by a decrease (increase) in the monsoon rainfall. The surface air temperature over the Indian region were found to show increase in positive and decrease during negative PDO phases (Krishnan and Sugi 2003). The sea level pressure (SLP) anomalies over south and southeast Asia showed dynamically consistent out-of-phase pattern with the SLP anomalies over the tropical central-eastern Pacific (Krishnan and Sugi 2003). Thus, the remote influence of PDO on the SW monsoon is associated with prominent signals in the tropical and southern Indian Ocean (Krishnan and Sugi 2003).

\section{Conclusions}

In our analysis of in-situ rain-gauge based gridded rainfall dataset extending over 1951-2007, no systematic significant long term trends in the parameters of the temporal within-season profile of SW monsoon rainfall were observed over western India. The onset date as well as fixed percentile accumulation of monsoon rains, although going through large-scale quasi-periodic variations, do not indicate any long-term statistically significant trends. The results presented here for the western Indian region are generally consistent with earlier studies based on different datasets (e.g., Ghosh et al. 2009; Guhathakurta et al. 2011) and model projections. However, it is interesting to note that over the last decade, i.e., during 2000-2007, the seasonal rainfall amount, as well as seasonal span of SW monsoon over western India, does indicate a gradual increase. For the entire period of 1951-2007, statistical analysis does show a slow +0.12 days/year trend in the span of monsoon season.

The observed long term decadal scale variations in the within-season rainfall variability are analysed in terms of the influence of Pacific Decadal Oscillation, and this brings out the interesting result that PDO produces a definitive influence on August rainfall over western Indian region. Daily variations in rainfall anomaly show opposite characteristics during negative and positive phases of PDO. The above-normal rainfall $(>25 \%)$ is found during starting phase of monsoon in negative PDO.

Further studies, involving longer datasets incorporating more recent years and covering different regions of the country, are required to bring out a detailed picture of climatological trends/changes in within-season temporal profile of SW monsoon over different parts of India. 


\section{Acknowledgements}

PDO data are obtained from Joint Institute for the Study of the Atmosphere and Ocean (JISAO), University of Washington, USA. Funding for the study is provided by Ministry of Earth Sciences (MoES), Govt. of India under the IndoUK Changing Water Cycle Programme (MoES/ NERC/16/02/10 PC-II). We are thankful to the reviewers and the editor for their suggestions.

\section{References}

Anderson G C and Nash D J 2013 Long-term variability in the date of monsoon onset over western India; Clim. Dyn. $402589-2603$.

Goswami B N, Venugopal V, Sengupta D, Madhusoodanan M S and Xavier P K 2006 Increasing trend of extreme rain events over India in a warming environment; Science 314 1442-1445.

Ghosh S, Lunia V and Gupta A 2009 Trend analysis of Indian summer monsoon rainfall at different spatial scales; Atmos. Sci. Lett. 10 285-290.

Ghosh S, Das D, Kao S C and Ganguly A R 2011 Lack of uniform trends but increasing spatial variability in observed Indian rainfall extremes; Nat. Clim. Change 2 86-91.

Guhathakurta P, Rajeevan M, Sikka D R and Tyagi A 2015 Observed changes in southwest monsoon rainfall over India during 1901-2011; Int. J. Climatol. 35 1881-1898.

Guhathakurta P, Sreejith O P and Menon P A 2011 Impact of climate change on extreme rainfall events and flood risk in India; J. Earth Syst. Sci. 120 359-373.

Jagannathan P and Bhalme H N 1973 Changes in the pattern of distribution of southwest monsoon rainfall over
India associated with sunspots; Mon. Wea. Rev. 101 694-700.

Kishtawal C M, Niyogi D, Tewari M, Pielke R A and Shepherd J M 2010 Urbanization signature in the observed heavy rainfall climatology over India; Int. J. Clim. 30 1908-1916.

Krishna Kumar K, Patwardhan S K, Kulkarni A, Kamala K, Rao Koteswara K and Jones R 2011 Simulated projections for summer monsoon climate over India by a highresolution regional climate model (PRECIS); Curr. Sci. 101(3) 312-326.

Krishnan R and Sugi M 2003 Pacific decadal oscillation and variability of the Indian summer monsoon rainfall; Clim. Dyn. 21 233-242.

Mantua N J, Hare S R, Zhang Y, Wallace J M and Francis R C 1997 A Pacific decadal climate oscillation with impacts on salmon; Bull. Am. Meteorol. Soc. 78 1069-1079.

Rajeevan M, Bhate J, Kale J D and Lal B 2006 High resolution daily girded rainfall data for the Indian region: Analysis of break and active monsoon spells; Curr. Sci. 91(3) 296-306.

Ramanathan V, Crutzen P J, Kiehl J T and Rosenfeld D 2001 Aerosols, climate, and the hydrological cycle; Science $2942119-2124$.

Satyanarayana P and Srinivas V V 2008 Regional frequency analysis of precipitation using large-scale atmospheric variables; J. Geophys. Res. 13(D24110), doi: 10.1029/2008JD010412.

Sinha P, Mohanty U C, Kar S C, Dash S K, Robertson A W and Tippett M K 2012 Seasonal prediction of the Indian summer monsoon rainfall using canonical correlation analysis of the NCMRWF global model products; Int J. Clim. 33 1601-1614.

Tyagi A, Mazumdar A B, Khole M, Gaonkar S B and Devi S 2011 Re-determination of normal dates of onset of southwest monsoon over India; Mausam 62 321-328.

Yadav R K 2016 On the relationship between Iran surface temperature and north-west India summer monsoon rainfall; Int. J. Clim., doi: 10.1002/joc.4648. 